EXEMPLARIa Classica

Journal of Classical Philology

20, 2016, pp. 239-246

ISSN 1699-3225

\title{
ATLAS DEL MUNDO CULTURAL TARDO-ANTIGUO. A PROPÓSITO DE LA EDICIÓN DE LA VIDA DE LOS FILÓSOFOS Y SOFISTAS DE EUNAPIO DE SARDES.
}

Richard Goulet, Eunape de Sardes: Vies de philosophes et de sophistes, Collection des Universités de France. Série grecque, 508. Paris: Les Belles Lettres, 2014, xxiv + 1120 pp. (2 vols.) ISBN 978-2-251-00592-8.

Una lectura mínimamente atenta a la edición de las Vidas de los filósofos $y$ sofistas (VS) de Eunapio de Sardes a cargo de Richard Goulet implica adentrarse en los entresijos culturales, históricos y religiosos de la Antigüedad tardía. La exhaustividad de la labor histórico-filológica de este trabajo es tal que disuade al lector que quiera escribir sobre esta edición de componer una reseña meramente descriptiva que no haría justicia a esta obra que se puede calificar como el magnum opus del profesor Goulet. Los dos volúmenes cuidadosamente editados contienen dieciséis capítulos, varios apéndices prosopográficos y bibliográficos así como numerosos indices relativos a la transmisión textual de la obra de Eunapio y a las características estilísticas de su prosa. Tal plétora de materiales conforma un estudio completo y, sobre todo, armonizado por la correcta interrelación de los capítulos que lo componen. Este gran esfuerzo es de agradecer puesto que, a pesar del auge de los estudios tardo-antiguos durante las últimas décadas, ha sido más frecuente encontrar alusiones a la obra de Eunapio en las notas a pie de página que en el título de artículos y monografías. Así, sus VS han sido principalmente empleadas como una fuente tangencial usada para suplementar o cotejar la información acerca de las élites culturales del mundo antiguo. De hecho, una breve monografía de Robert Penella (Greek Philosophers and Sophists in the Fourth Century AD: studies in Eunapius of Sardis, Leeds 1990) constituye uno de los pocos intentos reseñables por estudiar de forma exhaustiva las VS -excepción hecha, claro está, de los artículos y trabajos parciales que Goulet ha dedicado a Eunapio durante cuatro décadas.

Ciertamente, es muy poco lo que se conoce de la vida de Eunapio y de su relación con los protagonistas de su obra. Goulet dedica las primeras páginas del primer volumen (pp. 5-23) de la edición a intentar solventar los problemas cronológicos que plantean las referencias internas que el propio Eunapio aporta acerca de su educación en Atenas cotejando la información con otras fuentes coetáneas (e.g., la Crónica de Jerónimo) y, especialmente, sometiendo 
a un análisis lingüístico algunas expresiones recurrentes en Eunapio con el objetivo de determinar con precisión el matiz temporal que aportan (nótese, por ejemplo, su estudio -vol. I, pp. 10-11-acerca de las implicaciones del uso

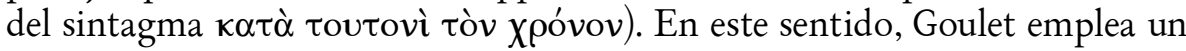
método similar al que R.C. Blockley usó en su edición de los fragmentos de historiografía tardo-antigua al trazar un perfil biográfico de Eunapio en el que el énfasis se pone en la interpretación de la información que se encuentra en los textos del propio autor ${ }^{1}$.

Tras este breve capítulo introductorio, el primer volumen de la edición disecciona muy diversos aspectos de la producción literaria de Eunapio. En primer lugar, el centro de atención del estudio gira en torno a la edición de las $V S$ que Goulet ha seguido - principalmente, el texto del Laurentianus Plut. 86.7. La revisión del texto es, en este caso concreto, especialmente pertinente dado que a pesar de la reciente aparición de ediciones de las VS de Eunapio, las referencias y citas presentes en la bibliografía moderna se valen de la edición de Wilmer Cave Wright, un trabajo de gran valía en su tiempo pero ya desfasado y obsoleto ${ }^{2}$. Aunque en las notas al texto y a la traducción del segundo volumen de su edición Goulet incide en aquellos aspectos relacionados con la datación, fuentes y arquitectura interna de las $V S$, el primer volumen (pp. 95-102) ofrece un esbozo general de estos temas. En este sentido, uno de los mayores aciertos de Goulet es complementar el análisis de las VS con los fragmentos de la Historia que Eunapio compuso acerca de los eventos transcurridos entre el reinado de Claudio II (268-270) y los primeros años del siglo V. La pertinencia de dedicar un buen número de páginas (vol. I, pp. 35-95) a esta obra fragmentaria se justifica por la complementariedad entre las VS y la Historia, como muestra el interés de Eunapio por remarcar las alusiones en la VS a la Historia que Goulet sintetiza en una tabla (vol I, pp. 42-7). Aunque se echan en falta comentarios que aludan a otros referentes de la historiografía tardo-antigua tan representativos como Sócrates Escolástico, Sozomeno, Zósimo o Teodoreto de Ciro, el objetivo de Goulet al estudiar la Historia de forma tan detallada consiste en intentar determinar el objetivo general de la obra literaria de Eunapio (vol. I, p. 107): presentarse como "l' héritier et le mandataire d'une race d'intellectuels en voie de disparition”. A nivel literario, esta actitud de considerarse una suerte de albacea del legado

${ }^{1}$ R. C. Blockley, The Fragmentary Classicising Historians of the Later Roman Empire. Eunapius, Olympiodorus, Priscus and Malchus, Leeds 1981, 1-26. Para un perfil biográfico menos exhaustivo pero más divulgativo, vid. D. Rohrbacher, The Historians of Late Antiquity, London-Nueva York 2002, 64-72.

${ }^{2}$ En los últimos años se han publicado tres nuevas ediciones (M. Civiletti, Eunapio di Sardi. Vite di filosofi e sofisti, Milán 2007; O. D’Jeranian, Eunape de Sardes. Vies de philosophes et de sophistes, París 2009; M. Becker, Eunapios aus Sardes. Biographien über Philosophen und Sophisten, Stuttgart 2013) que han reemplazado la de W. C. Wright, Philostratus and Eunapius, Londres-Cambridge (Mass.) 1921.

ExClass 20, 2016, 239-246 
clásico en un periodo de importantes transformaciones a todos los niveles implicaba, como se aprecia a lo largo de su producción literaria, la alternancia en el uso del encomio y del vituperio cuando se trataba de narrar los eventos y personajes de los siglos III-IV.

En efecto, una constante que comparten la VS y la Historia es el propósito de Eunapio de testimoniar lo que Goulet ha dado en denominar "la microsociété des intellectuels païens" (vol.I, p.125). Considero que el término "microsociété" es especialmente acertado dado que desplaza el foco de atención de interpretaciones excluyentes como el etiquetado de los miembros de las elites culturales bajo denominaciones excesivamente simplistas (filósofos, sofistas y médicos) hacia contextos compartidos por los pepaideumenoi. Así, Goulet enfatiza la semejanza de valores e influencias de esas "bibliotecas andantes" que Eunapio refleja en su VS y que compartieron un modelo educativo fundamentado en la paideia de raigambre clásica. Longino, por ejemplo, es

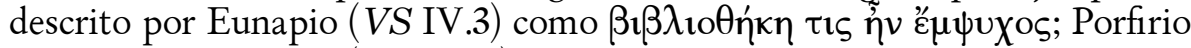

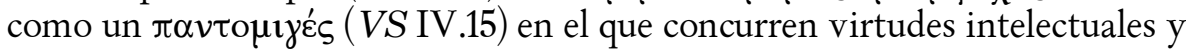
éticas. Igualmente, Eunapio nos relata que Edesio fue considerado como un

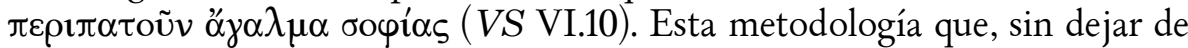
lado la taxonomía que clasifica a los intelectuales tardo-antiguos, prioriza el análisis del Zeitgeist cultural desde un punto de vista sincrónico favorece un conocimiento más dinámico e integrador del poliédrico mundo intelectual tardo-antiguo. Para Goulet, por lo tanto, la prioridad parece estribar en describir los mecanismos y valores que cohesionaron esas comunidades. En este sentido, al aplicar los preceptos de los trabajos más recientes adscritos a esta metodología ${ }^{3}$, Goulet coincide con los planteamientos de la monografía de Kendra Eshleman The Social World of Intellectuals in the Roman Empire (Cambridge 2012). La obra de Eshleman explora los mecanismos socio-culturales de época imperial que se activaban para validar estrategias de inclusión o exclusión en "micro-sociedades" como las descritas por Eunapio al tiempo que destaca el énfasis que se ponía en otro concepto muy presente en las VS: la importancia de la idea de "sucesión" dentro de las comunidades culturales de época imperial y tardo-antigua ${ }^{4}$. Así pues, Goulet continúa una línea de investigación tan fructífera como especialmente indicada para una obra como las $V S$ en la que la sucesión en las comunidades de conocimiento es el hilo conductor.

Los capítulos 5-7 del primer volumen se ocupan de las figuras del filósofo, del sofista y del médico en las VS siguiendo un esquema similar consistente

${ }^{3}$ S. Elm, Sons of Hellenism, Fathers of the Church: Emperor Julian, Gregory of Nazianzus, and the vision of Rome, Berkeley 2012; E. Watts, The Final Pagan Generation, Berkeley 2015.

${ }^{4} \mathrm{Al}$ respecto, léase P. P. Fuentes González, "En defensa del encuentro entre dos Perros, Antístenes y Diógenes: historia de una tensa amistad”, $C F C(G) 23,2013,225-67$.

ExClass 20, 2016, 239-246 
en unas breves indicaciones generales encaminadas a configurar un marco referencial en el que esbozar los nombres y las relaciones entre esas figuras cuyos casos concretos deben analizarse con el texto, la traducción y las notas del segundo volumen. La utilidad de esta metodología se aprecia con mayor claridad en el capítulo 5 dedicado a los filósofos. Además del ya mencionado resumen biográfico de cada filósofo, hay dos aspectos que merecen ser destacados: en primer lugar, reseñar que Eunapio presenta (p. 159) "au total six générations de philosophes platoniciens ou néoplatoniciens" desde Plotino hasta los sucesores de Crisantio de Sardes. A pesar de que los filósofos biografiados pertenecieron a la escuela neoplatónica, resulta sorprendente que las $V S$ no profundicen en los preceptos filosóficos de esta escuela, si bien ello no quiere decir que la filosofía platónica esté completamente ausente de la obra de Eunapio. Las referencias al corpus platónico están supeditadas al estilo alusivo imperante en la literatura tardo-antigua, tal y como argumenta G. Kelly en su estudio de otra obra historiográfica, la Historia de Amiano Marcelino ${ }^{5}$. Así, en lugar de mostrar su conocimiento de la filosofía platónica mediante paráfrasis o citas directas, Eunapio prefiere aludir mediante guiños intertextuales a los diálogos platónicos al retomar el vocabulario o las metáforas empleadas por Platón para caracterizar a los filósofos neoplatónicos de sus VS (e.g., V.9, 28; VI, 36, 114; VII, 43). En este contexto, merece una mención aparte el empleo que hizo Eunapio de la figura de Sócrates. Los perfiles biográficos de los filósofos Edesio (VS VI, 10-12) y, sobre todo, de Crisantio de Sardes (VS XXIII, 20-35) se construyen tomando a Sócrates como modelo a seguir. A pesar de que no se trata de una estrategia literaria innovadora (en el mismo siglo IV el filósofo Temistio recurrió frecuentemente a Sócrates como epítome de la ejemplaridad de la vida filosófica), esta cumple una función a distintos niveles interpretativos en el plan general de la obra de Eunapio, tal y como ha demostrado J. Campos en un reciente estudio ${ }^{6}$. En segundo lugar, es preciso destacar los ilustres ausentes en las VS de Eunapio. No sin razón, Goulet se pregunta sorprendido por la ausencia de personajes del calado intelectual de Siriano, Eugenio, Temistio, Teón o su hija Hipatia. Hay que descartar por completo que Eunapio no conociera sus obras, dado que en el mundo de los pepaideumenoi tardo-antiguos las interacciones culturales eran permanentes. Desavenencias doctrinales y rivalidades personales son hipótesis que explicarían estas ausencias pero que, por el momento, carecen de un sustento argumental definitivo.

${ }_{5}^{5}$ G. Kelly, Ammianus Marcellius: the Allusive Historian, Cambridge 2008.

${ }^{6}$ Agradezco al profesor J. Campos Daroca que me haya permitido leer su trabajo (en prensa) "Socrates amongst the Holy Men. Socratic Paradigms and Styles in Eunapius' Lives". Sobre el empleo de Sócrates como modelo para la бúyкрıбıৎ literaria, vid. N. Loraux, Las experiencias de Tiresias (Lo masculino y lo femenino en el mundo griego), Barcelona 2004, 359-64 (traducción de C. Serna y J. Pòrtulas).

ExClass 20, 2016, 239-246 
El capítulo 6 se centra en la descripción de la capacidad oratoria y habilidades performativas de los sofistas (vol I, pp. 208-25). Este catálogo de vitia et virtutes orationis está encaminado a poner de relieve el carácter agonístico del periodo, ejemplificado por Goulet en las páginas dedicadas a explicar las disputas entre sofistas por acceder a la categoría de sofista oficial de las principales metrópolis de la parte oriental del Imperio Romano (vol. I, pp. 188-92, 225-44). Todo ello se enmarca en el contexto de la enseñanza de la paideia en la Antigüedad tardía, una línea de investigación muy fructífera explotada por E. Watts (especialmente, en su City and school in late Antique Athens and Alexandria, Berkeley 2006) y que Goulet sigue de cerca al centrarse en la fuerte rivalidad entre las distintas escuelas por captar alumnos (vol. I, pp. 198-208). En efecto, las fuentes tardo-antiguas destacan la alta competitividad en el mundo escolar en la Atenas del siglo IV (e.g., Lib. Or. 1.11-22, 53, 85; Gregorio de Nacianzo, Or. 5.39; 7.13; 43.15). Eunapio conjuga el relato de los de vitia et virtutes orationis y el tema de la competitividad en el mundo escolar al enumerar las virtudes del que fuera su maestro, Proheresio, en un pasaje de carácter netamente agonístico (VS IX 7-26): tras la detención de los alumnos de Julián de Capadocia y los de su rival, Apsines, el procónsul de Atenas decidió que el asunto se dirimiera en un agon al estilo judicial. Tras el fiasco oratorio de Temístocles, el alumno aventajado de Apsines, Proheresio hizo ganar la causa a Julián de Capadocia y al resto de sus compañeros tras declamar tan brillantemente que el procónsul y el propio Apsines acabaron por ovacionarle (VS IX 25-26). De hecho, el extenso relato de la vida de Proheresio que compuso Eunapio se estructura en torno a los agones oratorios en los que Proheresio dio muestras de sus altas capacidades oratorias (VS X 25-71, 76-79). Aunque no tan prolijo en detalles, el relato del sofista Libanio de Antioquía confirma que Eunapio tenía especial interés en la crítica del estilo oratorio y literario de los personajes de sus VS. Según su criterio (VS XVI 13-17) y contrariamente a lo que opinó la tradición escolar

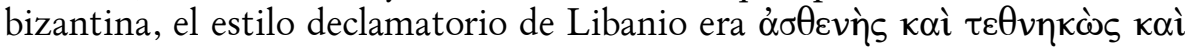
ắ vous, si bien su estilo en el resto de subgéneros retóricos mereció un juicio más positivo de Eunapio.

El breve capítulo 7 está dedicado a los médicos, una figura especialmente problemática de estudiar por dos motivos principales: en primer lugar, porque un estudio diacrónico de los médicos en la antigüedad nos obliga a desterrar los anacronismos que evoca el término en su acepción actual en favor de la visión de la figura del médico como un intelectual. En segundo lugar, como deja a las claras Goulet en este capítulo, un análisis sincrónico de esta figura revela un panorama misceláneo en el que diversas nomenclaturas y prácticas médicas se solapaban. Iatrosofistas, philiatroi y médicos de sólida formación como Oribasio, el médico personal del emperador Juliano al que Eunapio dedica un extenso capítulo (VS XXI), conformaban un grupo heterogéneo del que apenas se aporta información relativa a aspectos concretos de su 
disciplina. Así, el interés de Eunapio no es tanto la práctica de la medicina en sí como la formación cultural de los médicos. Por ejemplo, las líneas dedicadas a Ninfidiano y a Zenón (VS XVIII, XIX) resaltan las dotes oratorias de estos dos pepaideumenoi con vocación médica. En este sentido, parece haber un sentido de continuidad con algunos textos de Galeno (e.g., Sobre la localización de las enfermedades; Sobre el pronósticos) en los que él mismo dedicaba largos pasajes a narrar la actio que llevó a cabo cuando se trataba de proporcionar un diagnóstico o enunciar una teoría frente a rivales de otras escuelas médicas. Del mismo modo, las interacciones entre retórica y medicina no se reducían al desarrollo de competencias oratorias por parte de los médicos, sino que en textos de naturaleza retórica la medicina o la asimilación del autor o del destinatario del discurso con la figura del médico que restaura la salud de un "paciente" (i.e., una ciudad o el Imperio Romano) constituyó un leitmotiv recurrente (e.g., Lib. Or. 52.32-36).

Tras este capítulo, Goulet dedica el resto del volumen I a la contextualización histórico-cultural en la que transcurrieron las vidas de todos estos pepaideumenoi. Los capítulos 8-9 investigan acerca de la importancia de las diversas metrópolis de la parte oriental del Imperio Romano y de los acomodados orígenes sociales (vol. I, p. 278: "c'est le monde de la noblesse des grandes villes d'Orient”) de sus biografiados. El capítulo 10 aborda de manera muy escueta la formación intelectual de los pepaideumenoi. La importancia del aprendizaje y praxis de la paideia clásica se ha convertido en la piedra angular de cualquier estudio de la literatura tardo-antigua debido no solamente al interés de su contenido sino también a su valor como el requisito principal para medrar en el competitivo escenario cultural tardo-antiguo, tal y como ha demostrado L. van Hoof en un reciente estudio $(2013)^{7}$ o el propio Goulet al mencionar la conocida como "ley escolar" del emperador Juliano por la que se impedía impartir docencia a todos aquellos profesores que no comulgaran con el contenido de la paideia (vol. I, pp. 15-20). Sin duda, merece la pena investigar en los textos del siglo IV con el objeto de estudiar las distintas concepciones de la paideia en el periodo imperial y tardo-antiguo:

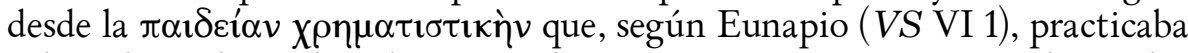
Edesio hasta la paideia de contenido cristiano que intentaron implantar los Apolinares como reacción al edicto de Juliano según el historiador Sócrates Escolástico (HE III.16).

La recurrente presencia del agon en el mundo educativo y cultural es, en mi opinión, una de las líneas de investigación más interesantes tanto por la plétora de textos sin investigar de la que disponemos (por ejemplo, el discurso 55 de Libanio de Antioquía versa sobre los problemas de la $\alpha \dot{\pi} \sigma \tau \tau \alpha \sigma i \alpha$ y el traslado de una escuela a otra por parte de los alumnos) como por las cuestiones

${ }^{7}$ L. van Hoof, "Performing Paideia: literature as an Instrument for Social Promotion in the Fourth Century A.D.”, CQ 63, 2013, 387-406.

ExClass 20, 2016, 239-246 
que trae a colación y que Goulet investiga en los capítulos 11-13: el lugar de los representantes de la cultura helena en un Imperio en el que el cristianismo se fue convirtiendo, poco a poco, en acólito al poder imperial. El paradigma historiográfico que preconizaba un enfrentamiento entre paganos y cristianos está dejando paso a una metodología en la que las etiquetas religiosas son válidas a nivel descriptivo pero fracasan al interpretar un mundo en el que los matices en la relación religión-cultura cobran una relevancia especial. Si desde hace unas décadas se viene criticando el uso del término "cristianismo"por agrupar tendencias que divergen entre sí en aspectos clave, en los últimos años los estudios de C. P. Jones (Between pagan and Christian, LondresCambridge (Mass.) 2014) se han impuesto al llamar la atención del error que supone usar el término "paganismo" como un concepto homogéneo cuando, en verdad, las actitudes ante el hecho religioso de un neoplatónico poco tendrían que ver con las de paganos apegados a la tradición como Libanio o más moderados en sus relaciones con el cristianismo como Temistio. Goulet recapitula lo tratado en estos capítulos para intentar delinear en su capítulo 14 cómo sería el "sage idéal”.

Hay un cambio total de registro en los capítulos 15-16. Así, partiendo de la opinión de Focio acerca del estilo literario y peculiaridades lingüísticas de Eunapio, Goulet disecciona los rasgos propios e influencias a nivel gramatical, sintáctico y estilístico de la VS. El capítulo 16 aborda la historia de la transmisión textual de las $V S$ al comentar numerosos aspectos relativos a la tradición textual de todos los manuscritos que contienen las VS (vol. I, pp. 439-455), si bien se destacan las conjeturas de Junius y de Giangrande. Esta información se amplía tras la traducción del volumen II con un supplementum emendationum (vol. II, pp. 109-27) y con concordancias entre las distintas ediciones (vol. II, pp. 289-300).

Finalmente, el primer volumen concluye con un apéndice prosopográficoen el que Goulet aporta la información básica de cada uno de los pepaideumenoi biografiados en las VS tomando como base la monumental obra propográfica encabezada por Jones (A. H. M. Jones; J. R. Martindale, J. Morris, The Prosopography of the later Roman Empire, Cambridge 1971-1992). En este sentido, este apéndice de Goulet se suma a los recientes intentos de Puech (B. Puech, Orateurs et sophistes grecs dans les inscriptions d'époque impériale, París 2002) y al más reciente coordinado por Janiszewski (P. Janiszewski et. al., Prosopography of Greek Rhetors and Sophists of the Roman Empire, Oxford 2015) por compilar información sobre los oradores y sofistas de época imperial.

Estos dos volúmenes son, en conclusión, mucho más que una muy buena edición textual. Se trata de un ejercicio de polymathía a cargo de un pepaideumenos contemporáneo que conjuga un puntilloso estudio literario e histórico con una traducción comentada a todos los niveles con un amplio y profundo apéndice de notas complementarias (vol. II, pp. 135-288). El mérito 
246 Alberto J. Quiroga: Atlas del mundo cultural tardo-Antiguo...

de esta edición de Richard Goulet consiste en conservar el prurito propio de una edición de Les Belles Lettres y en su capacidad para presentar de manera asequible el caleidoscópico mundo cultural y religioso de la Antigüedad tardía.

Alberto J. Quiroga Puertas

Universidad de Granada

aquiroga@ugr.es 